\title{
Early fault detection in SiC-MOSFET with application in boost converter
}

\author{
Detección de fallas en SiC-Mosfet con aplicación en un convertidor elevador
}

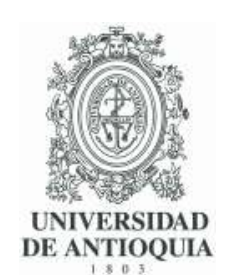

\author{
Leobardo Hernández-González ${ }^{1 *}$, Climaco Arvizu-Ogilvie ${ }^{1}$, Alejandro Tapia-Hernández ${ }^{2}$, Mario Ponce-Silva ${ }^{3}$, Abraham \\ Claudio-Sánchez ${ }^{3}$, Marco Rodríguez-Blanco ${ }^{4}$, Jesús Aguayo-Alquicira ${ }^{3}$ \\ ${ }^{1}$ ESIME Culhuacan, Instituto Politécnico Nacional, Av. IPN, S/N, C.P. 04430, Ciudad de México, México \\ ${ }^{2}$ Instrumentation and Driver HMI, Continental Automotive, Camino A La Tijera No. 3, C.P. 45640, Guadalajara, México \\ ${ }^{3}$ Centro Nacional de Investigación y Desarrollo Tecnológico, Interior Internado Palmira S/N, Col. Palmira, C.P. 62490, Cuernavaca, México \\ ${ }^{4}$ Departamento de Ingeniería Electrónica, Universidad Autónoma del Carmen No. 4 Esq. Avenida Concordia Col. Benito Juárez, C.P. \\ 24180, Cd. del Carmen, Campeche, México
}

\section{ARTICLE INFO: \\ Received April 09, 2017 \\ Accepted March 15, 2018}

\section{KEYWORDS:}

Semiconductor, silicon carbide, fault-detection

Semiconductor, carburo de silicio, detección de fallas
ABSTRACT: This paper presents the design of a fault detection circuit applied to a silicon carbide Mosfet (SiC-Mosfet). Fault detection is done by monitoring the behavior of the gate signal. The most important characteristic that has been reported in literature is quick detection since the evaluation is done while the SiC Mosfet is turning-on. With this method fast detection is allowed for short-circuit and open-circuit failure with small times for detection which prevents to spread the failure to the full system. To validate the fault detection circuit a boost converter with SiC-Mosfet was designed. Experimental results validate the reliability of the proposal.

RESUMEN: Este artículo presenta el diseño de un circuito de detección de fallas aplicado a Mosfet de carburo de silicio; la detección de falla es realizada a través del monitoreo de comportamiento de la señal de compuerta. Las más importantes características que se analizaron y se reportan son: rápida detección debido a que la evaluación se realiza en la conmutación a encendido, permitiendo la detección de fallas en corto circuito y circuito abierto; tiempos rápidos de detección lo que previene difusión de la falla al sistema completo. Para validar el circuito de detección fue diseñado un convertidor boost con SiC-Mosfet. Los resultados obtenidos validan la confiabilidad de la propuesta presentada.

\section{Introduction}

The development of power semiconductors based on materials with wide forbidden band like Silicon Carbide (SiC) has become a viable alternative to replace the actual Silicon power devices due to its advantages like: wider forbidden band $(2 x)$, higher electrons speed saturation $(2 x)$ and better thermal conductivity $(5 x)$. These advantages help to avoid the use of heatsinks improving switching frequency and reducing the switching losses with better stability against temperature [1-4]. The Power-MOS based on $(\mathrm{SiC})$ is one of the devices ready to replace the actual Power-MOS silicon solution mainly in applications with high temperature and high current density like power converters.

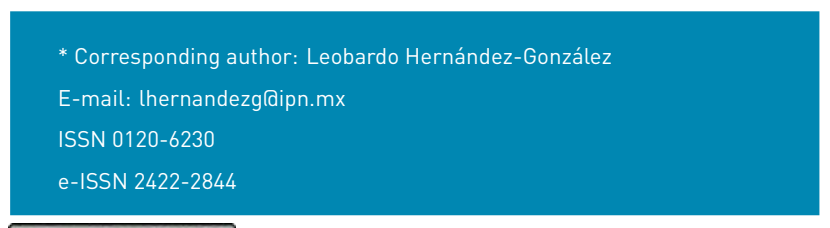

The electrical characteristics of the SiC-Mosfet require an early fault detection subsystem to isolate any fault as fast as possible avoiding the damage of the components and protecting the application. In literature have been reported different fault detection techniques based on the measurement of the collector voltage, collector current, gate voltage and the induced voltage from the inductance of the emitter wire for IGBTs [5-9]. However, the implementation of a fault detection circuit represents a higher cost with complex configurations and low performance for fault detection and reverses voltage transients. Other reported techniques are based on the measurement of the voltage level changes [10], deviation of the normalized current [11, 12], and the voltage slew rate $[13,14]$. These techniques are faster than those previous mentioned. However, to find the fault several measurements are necessary causing a late detection of the fault due to the complex analysis even in steady state and only for open-circuit fault condition.

In [15-17] have been showed that a correct analysis of the gate signal (IGBT Mosfet) allows a microseconds 
detection time. To apply a technique based on the gate behavior of the SiC-Mosfet is necessary to analyze the charge behavior of the internal capacitances $C_{G S}$ and $C_{G D}$ due to the small capacitance value $(1900 \mathrm{pF})$ and the gate charge less than $28 \mathrm{nC}$ for 1200Va25A [18].

In this paper is presented a novel fault detection technique based on the analysis of the SiC-Mosfet gate while is turning-on. Simulation and experimental results are shown for a boost topology. The theoretical analysis of the gate charge is included with simulation results of the fault detection system proposed and the experimental results to validate the proposal.

\section{Analysis of $\mathbf{V}_{G S}$ behavior when is turning-on}

In Figure 2 is showed the analytical behavior of the gate-source voltage and its dependency with the drain current for a non-fault condition. Due to the interaction between the SiC Mosfet and the external circuitry it is necessary to consider the kind of load [19]. The analysis of the load is showed in Figure ?? where $V_{T}$ is the threshold voltage, $V_{G 1}$ is the flat phase voltage and $V_{G M}$ is the maximum applied voltage to the converter. Each period of time represent a phase of $V_{G S}$ respecting $I_{D}$. The initial conditions for the analysis are: $V_{G S}=0, I_{D}=0$ and $V_{D S}=V_{D D}$

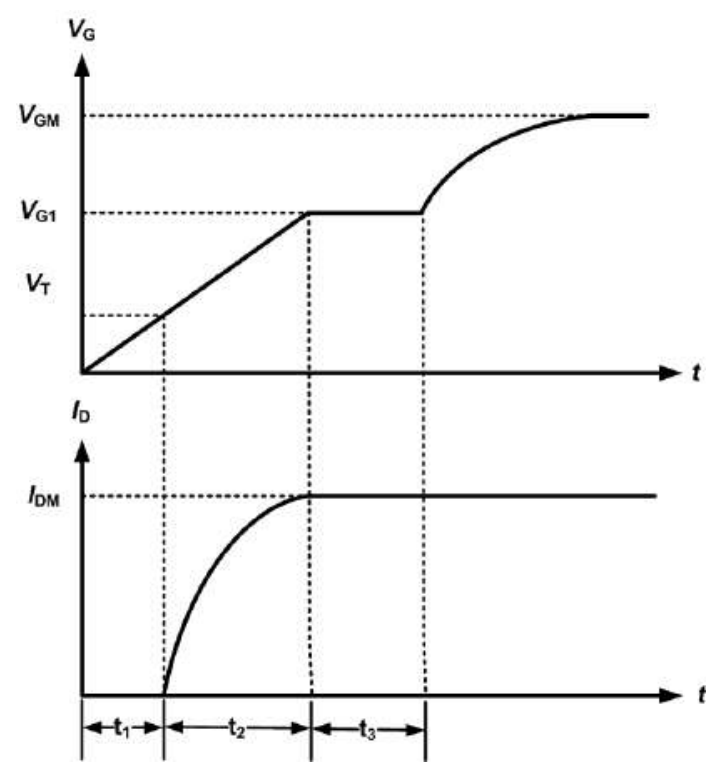

Figure 1 DRX patterns of spinel materials obtained by solid state: (a) $\mathrm{LiMn}_{2} \mathrm{O}_{4}$ and (b) $\mathrm{LiNi}_{0.5} \mathrm{Mn}_{1.5} \mathrm{O}_{4}$. Sol-gel: (c) $\mathrm{LiMn}_{2} \mathrm{O}_{4}$ and (d) $\mathrm{LiNi}_{0.5} \mathrm{Mn}_{1.5} \mathrm{O}_{4}$

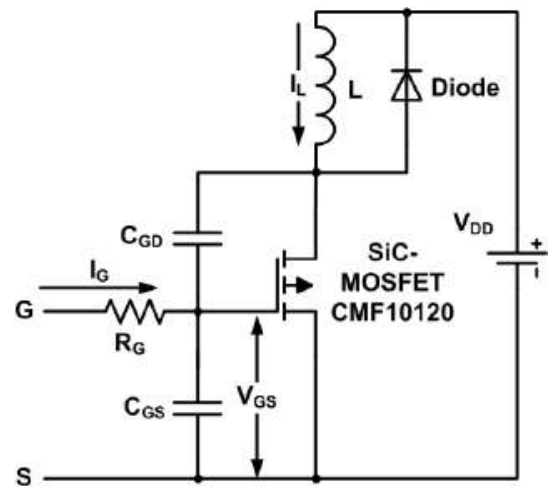

Figure 2 Equivalent circuit for the Mosfet to analyze the behavior of $V_{G S}$ while is turning-on

\section{1 Period $t_{1}$}

$V_{G S}$ depends of the charge $C_{G S}+C_{G D}$ through $R_{G}$, while it rises from zero to the activation level $V_{T}, I_{D}$ is $0 A$. This period of time is defined as turn-on delay and the behavior is given by (1).

$$
V_{G S}=V_{G M}\left\{1-e^{-\left[\frac{t}{R_{G}\left(C_{G S}+C_{G D}\right)}\right]}\right\}
$$

\subsection{Period $t_{2}$}

$V_{G S}>V_{T}$ this condition sets the current through the drain and is proportional to the gate voltage with a $g_{m}$ slew rate. Due to the Miller effect in the capacitance $C_{G D}$ the charge has an exponential behavior according with (2).

$$
I_{D}=g_{m}\left\{V_{G M}\left(1-e^{-\frac{t}{R_{G}\left(C_{G S}+C_{G D}\right)}}\right)-V_{T}\right\}
$$

\subsection{Period $t_{3}$}

$I_{D}$ has its maximum level given by the external load connected to the Mosfet. Because $I_{D}$ is constant the gate voltage is constant (flat phase) which is given by (3).

$$
V_{G 1}=V_{T}+\frac{I_{D M}}{g_{m}}
$$

Because $V_{G S}$ is constant, all the current flows through the capacitance $C_{G D}$, at the same time $V_{D}$ decreases near zero which forces the gate current to follow the charge of $C_{G D}$ (4).

$$
I_{G}=\frac{1}{R_{G}}\left[V_{G M}-\left(V_{T}+\frac{I_{D M}}{g_{m}}\right)\right]
$$

After period $t_{3}, C_{G D}$ is still charged forcing $V_{G S}$ to rise exponentially to the maximum value $V_{G M}$. 


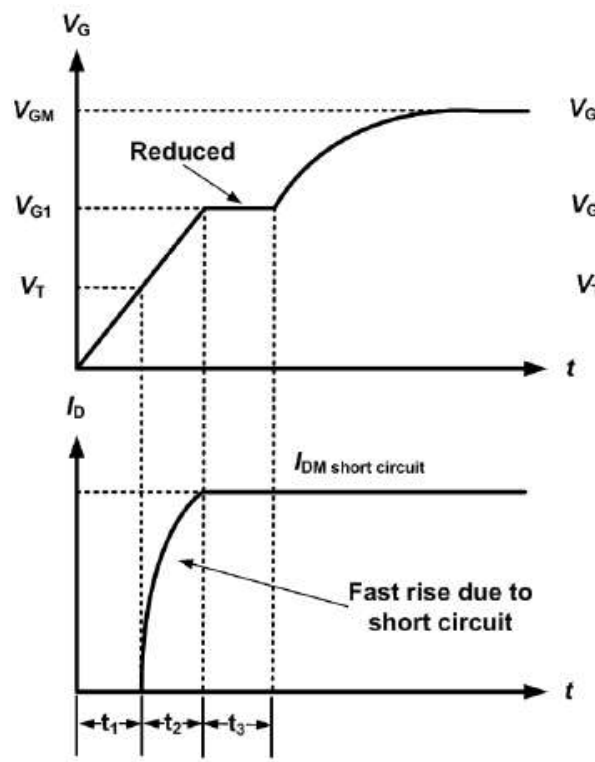

a)

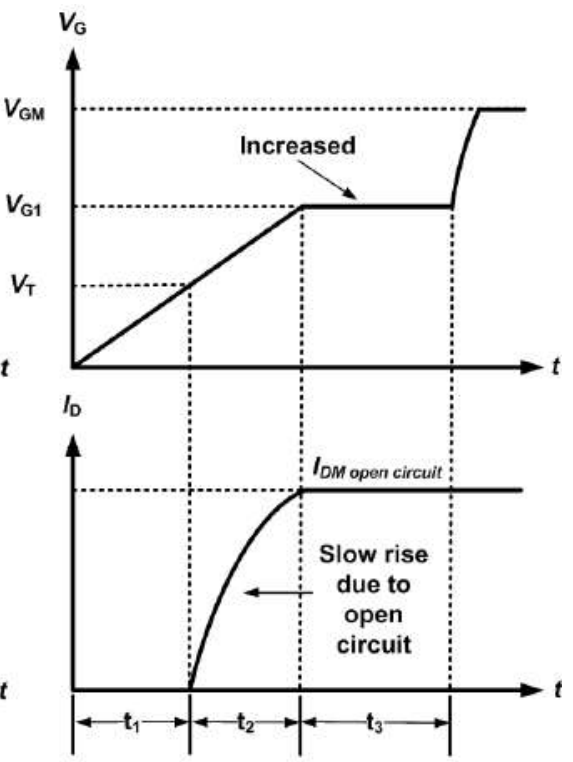

b)

Figure 3 Theoretical behavior for $V_{G S}$ for al short-circuit and b) open-circuit

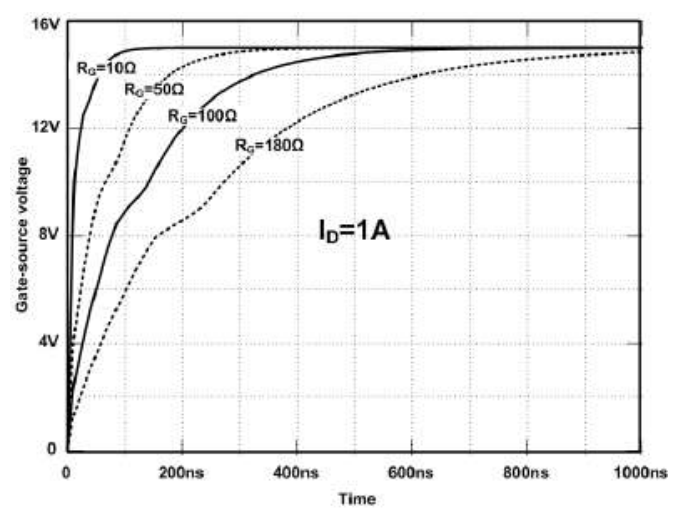

Figure $4 V_{G S}$ for $I_{D}=1 \mathrm{~A}$ with $R_{G}$ values of $10 \Omega, 50 \Omega, 100 \Omega$ and $180 \Omega$

From the presented behavior is observed the dependency of $I_{D}$ with respect to $V_{G S}$ during $t_{3}$ (flat phase). As can be seen on (3), if $I_{D}$ changes (short-circuit or open circuit fault) a change on $V_{G S}$ is induced. In Figure 3 is presented the theoretical behavior caused by short-circuit and open circuit fault condition.

\section{Simulation results when $V_{G S}$ is turning-on}

In order to select the appropriate thresholds during the flat phase of $V_{G S}$, the behavior of the SiC-Mosfet was simulated with different values of $I_{D}$ and $R_{G}$ for short-circuit and open-circuit faults.

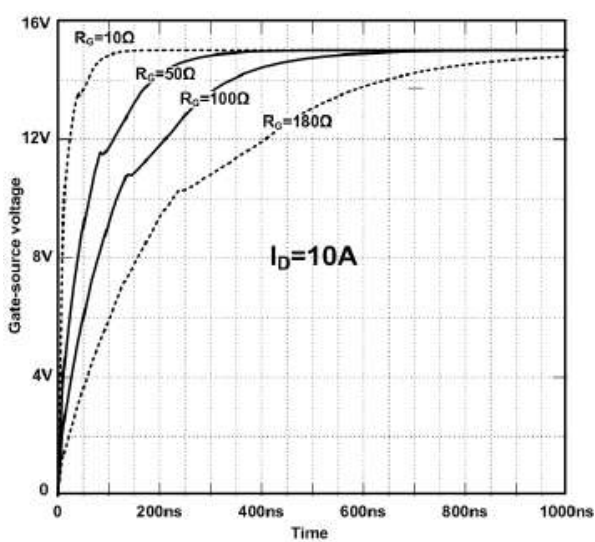

Figure $5 V_{G S}$ for $I_{D}=10 \mathrm{~A}$ with $R_{G}$ values of $10 \Omega, 50 \Omega, 100 \Omega$ and $180 \Omega$

The device used was the CMF10120 $\left(I_{D}=10 A\right.$, $V_{D S}=1200 \mathrm{~V}$ ) from Cree Company.

In Figures 4 and 5 is showed the behavior of $V_{G S}$ for $I_{D}=1 \mathrm{~A}$ and $10 \mathrm{~A}$ with $R_{G}$ variations. For $R_{G}=10 \Omega$ the dynamic of the $C_{G D}$ charge is incremented and the time of the flat phase is reduced. With $R_{G}=180 \Omega$ the dynamic of the $C_{G D}$ charge is reduced and the time of the flat phase is increased. In Figure 6 is showed the comparative of $V_{G S}$ for $I_{D}=1 \mathrm{~A}$ and $10 \mathrm{~A}$ with $R_{G}=180 \Omega$. From these results was concluded that $R_{G}=180 \Omega$ allows an optimal dynamic of the $V_{G S}$ charge for an appropriate experimental measurement with short-circuit and open-circuit fault conditions. 
Table 1 Zones comparator operation

\begin{tabular}{ccccccc}
\hline VZ1 & VZ2 & VZ3 & Z1 & Z2 & Z3 & Fault \\
\hline On & 0 & 0 & 1 & 0 & 0 & Short \\
On & On & 0 & 0 & 1 & 0 & None \\
On & On & On & 0 & 0 & 1 & Open \\
\hline
\end{tabular}

\section{Fault detection system}

Figure 7 shows the block diagram of the fault detection system based on [16, 17]. It is formed by a differential block, window voltage comparator, hysteresis comparator, ramp generator, zones comparator and the decision circuit.

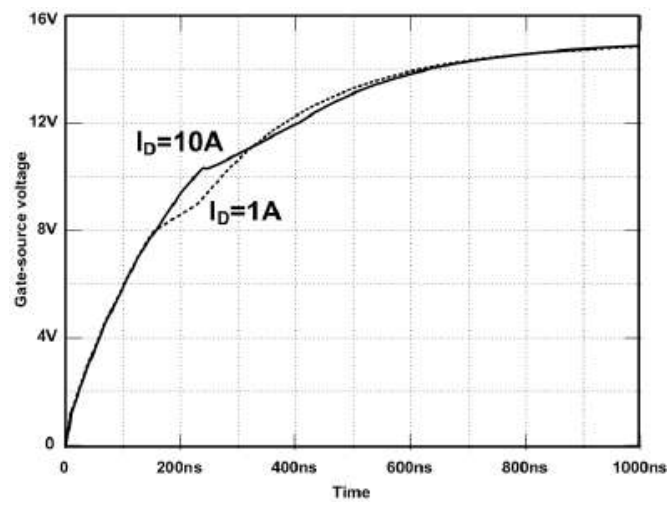

Figure 6 Behavior of $V_{G S}$ for $I_{D}=1 \mathrm{~A}$ and $I_{D}=10 \mathrm{~A}$ with $R_{G}=180 \Omega$
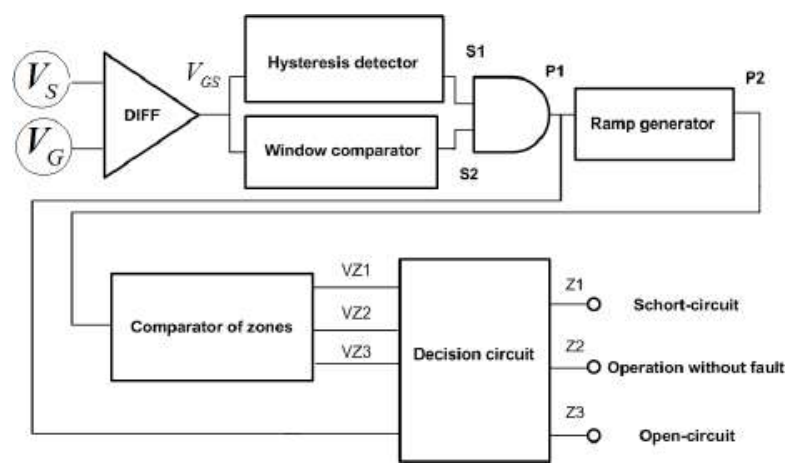

Figure 7 Block diagram for the fault detection circuit

The zones comparator works according with Table 1. For a non-fault condition only VZ1 and VZ2 thresholds are working. When a short-circuit fault occurs VZ1 is activated and when an open-circuit fault occurs VZ1, VZ2 and VZ3 are activated.

In Figure 8 simulation results are presented for a non-fault condition where the following responses are shown: differential circuit $V_{G S}$, hysteresis circuit S1, window comparator $\mathrm{S} 2$, logic multiplier circuit $\mathrm{P} 1=\mathrm{S} 1 * \mathrm{~S} 2$ and ramp generator $\mathrm{P} 2$ as function of the pulse width $\mathrm{P} 1$. In Figure 9 are showed the thresholds levels VZ1 and VZ2.

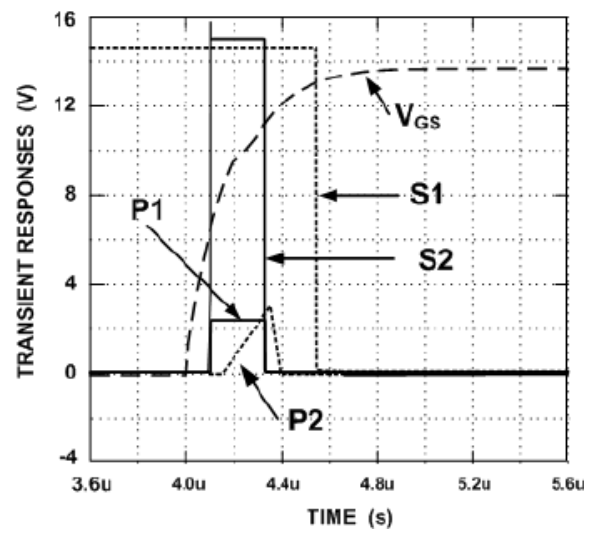

Figure 8 Simulation result for a non-fault condition

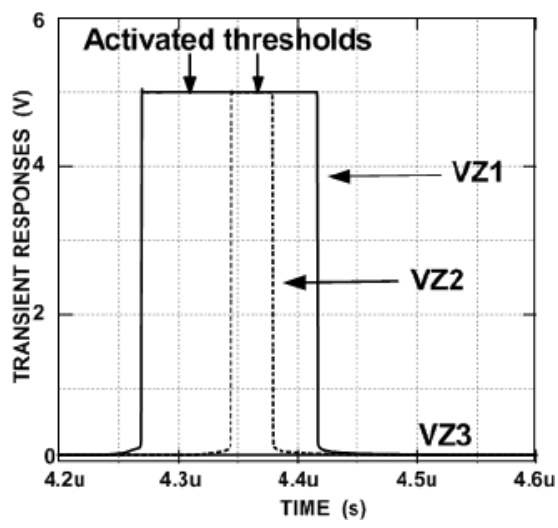

Figure 9 Simulation result of the zone comparator for a non-fault condition

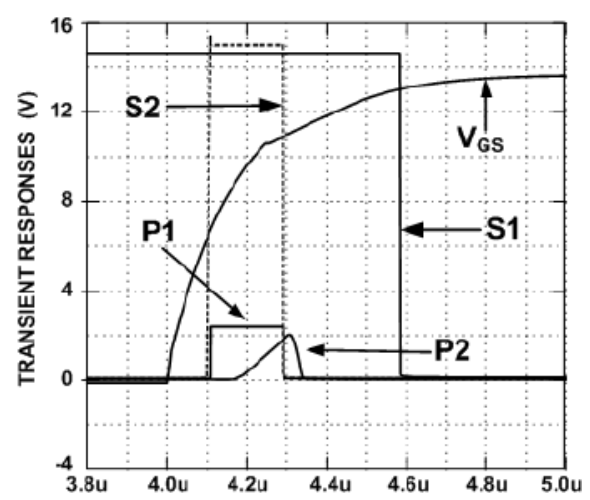

Figure 10 Simulation result of the fault detection circuit for a short-circuit fault condition

In Figure 10 are showed the simulation results for a 
short-circuit fault condition where can be seen that signal P2 has smaller amplitude due to the flat phase time reduction according with the drain current increment. In Figure 11 is showed the corresponding VZ1 threshold level.

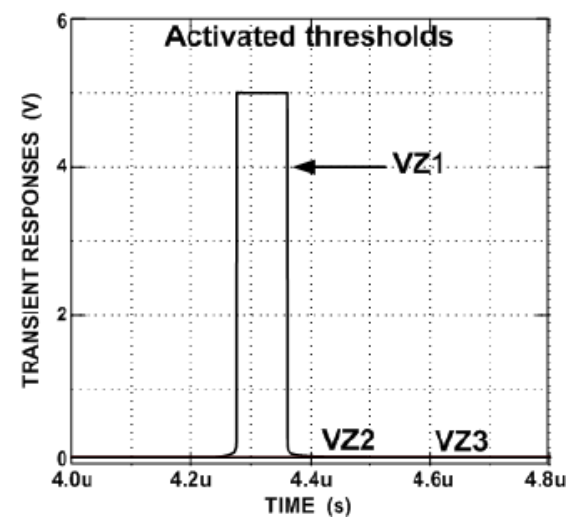

Figure 11 Simulation result of the zone comparator for a short-circuit fault condition

In Figure 12 are showed the simulation results for an open-circuit fault condition where can be seen that signal P2 has a bigger amplitude due to the flat phase time increment according with the increment of $I_{D}$. In Figure 13 are showed the corresponding threshold levels VZ1, VZ2 y VZ3.

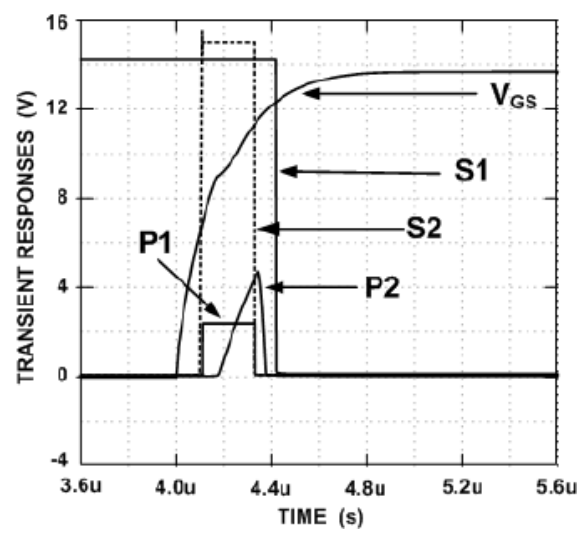

Figure 12 Simulation results of the fault detection circuit for an open-circuit fault condition

\section{Experimental results}

In order to validate the fault detection circuit a boost converter was designed with the following characteristics: $I_{\text {out }}=2 \mathrm{~A}, \Delta V_{0}=3 \mathrm{~V}, F_{S W}=50 \mathrm{kHz}$ and $\Delta I_{I N D}=1.2 A$ [20]. The circuit to detect, isolate and replace the damaged component is presented in Figure 14.

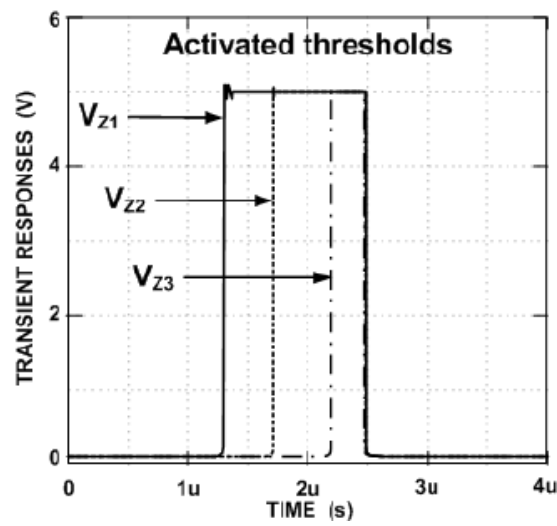

Figure 13 Simulation result of the zone comparator for an open-circuit fault condition

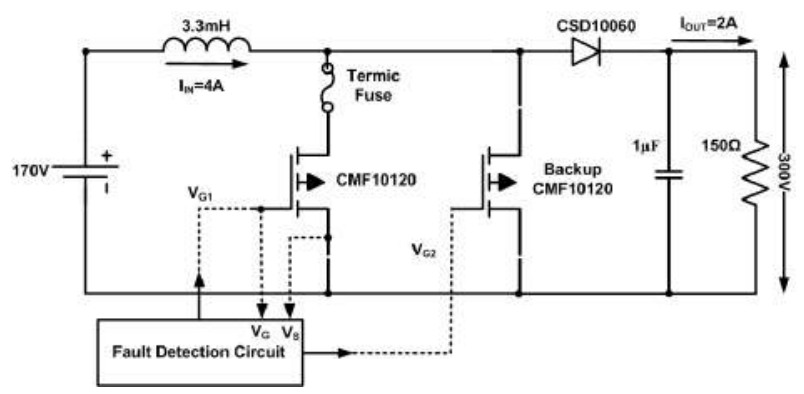

Figure 14 Test circuit to validate the fault detection system

On it is observed the replacement SiC-Mosfet which is activated immediately when the proposed fault detection system detects a fault condition.

In Figures 15, 16 and 17 are showed the signals $V_{G S}$ of the differential block for a non-failure condition, short-circuit failure and open-circuit failure. The yellow waveform is the gate signal of the SiC-Mosfet and the green waveform is the acquired signal from the instrumentation amplifier. From the waveforms is possible to verify the theoretical influence of the flat phase time, for a short-circuit failure condition the duration of the phase is reduce and for open-circuit failure condition the duration of the phase is incremented.

In Figures 18, 19 and 20 are showed the experimental results for the logic multiplier and the ramp generator for a non-fault condition, short-circuit fault and open-circuit fault. The green waveform is P1 and the yellow waveform is $P 2$.

It is possible to see that the ramp amplitude is reduced when a short-circuit fault condition occurs and is incremented when an open-circuit fault occurs. This behavior is according with the simulation results from Figures 8, 10 and 12 . 


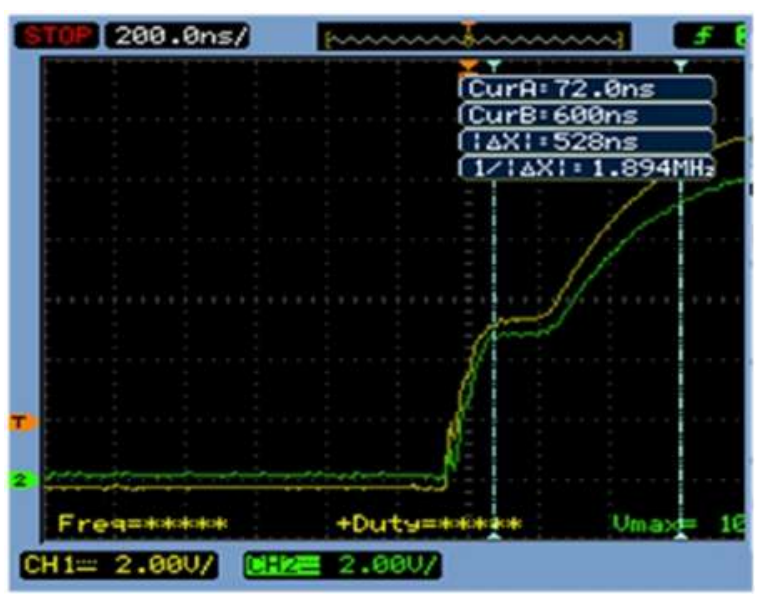

Figure $15 V_{G S}$ signal of the differential block for a non-fault condition

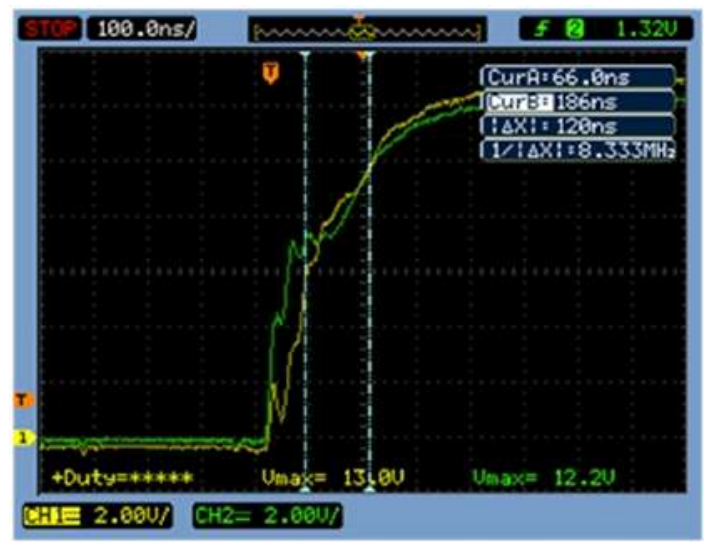

Figure $16 V_{G S}$ signal of the differential block for a short-circuit fault condition

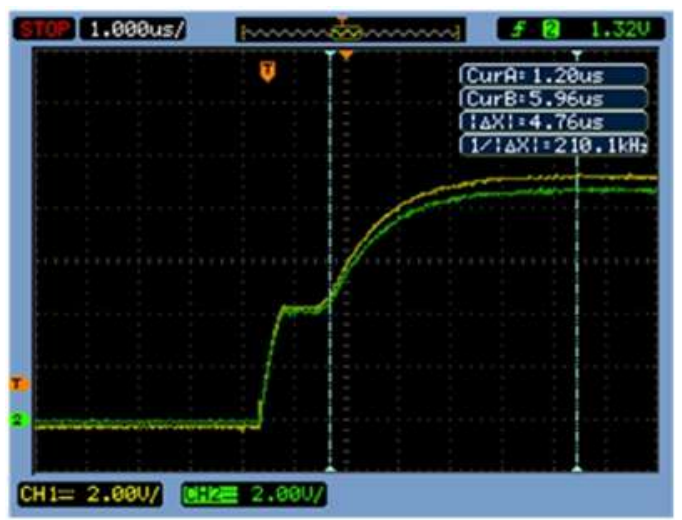

Figure $17 V_{G S}$ signal of the differential block for an open-circuit fault condition

In Figures 21, 22 and 23 are showed the experimental results of the decision block for: non fault, short-circuit fault and open-circuit fault conditions. Green waveform is the digital signal Z2 and yellow waveform is the digital

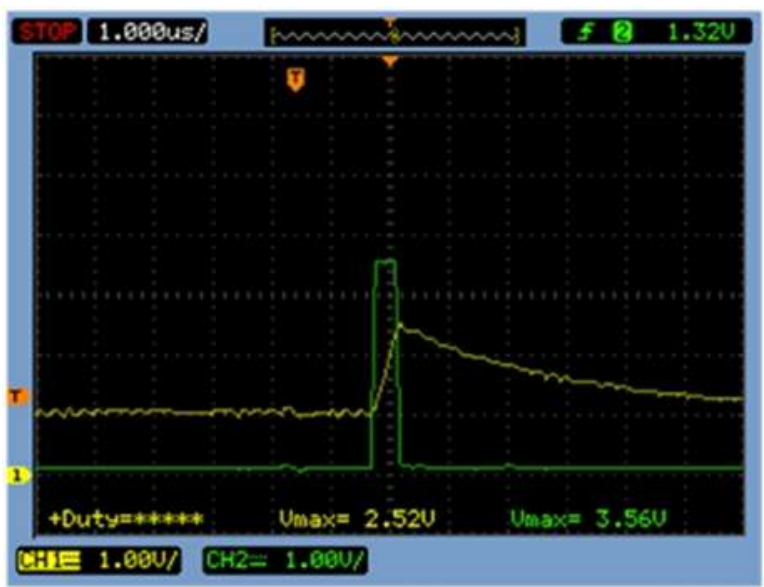

Figure 18 Experimental results of the logic multiplier and the ramp generator for a non-fault condition

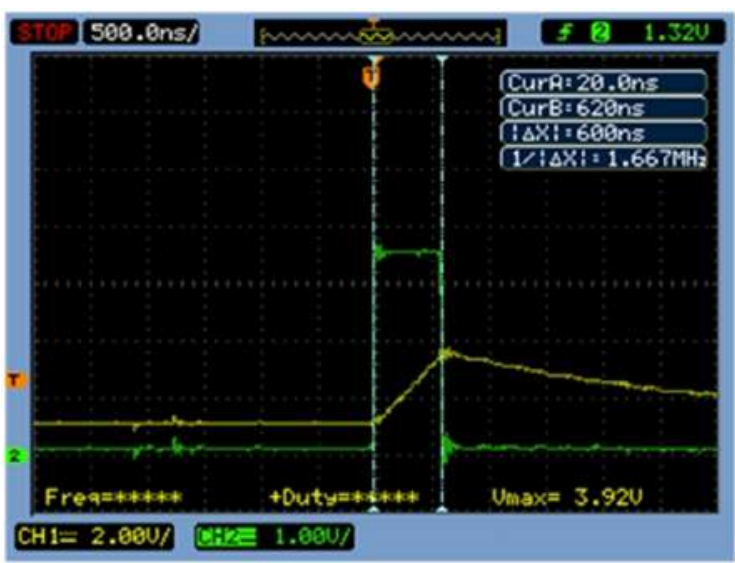

Figure 19 Experimental results of the logic multiplier and the ramp generator for a short-circuit fault condition

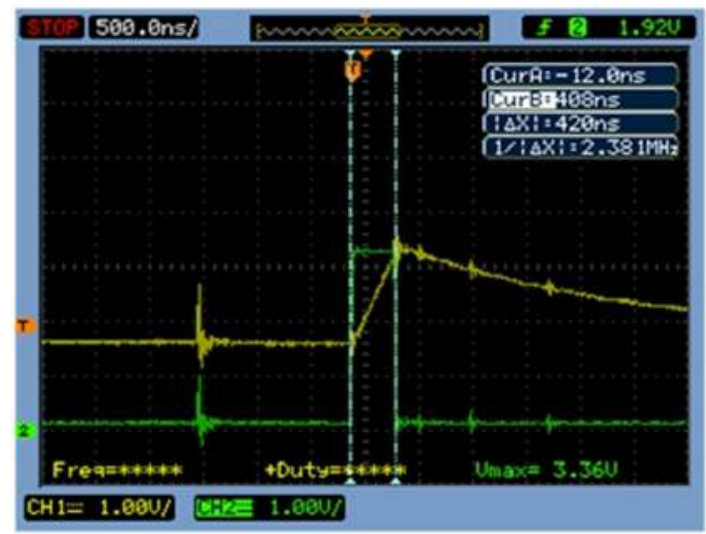

Figure $\mathbf{2 0}$ Experimental results of the logic multiplier and the ramp generator for an open-circuit fault condition

signal Z1. This behavior corresponds with the description on Table 1. 


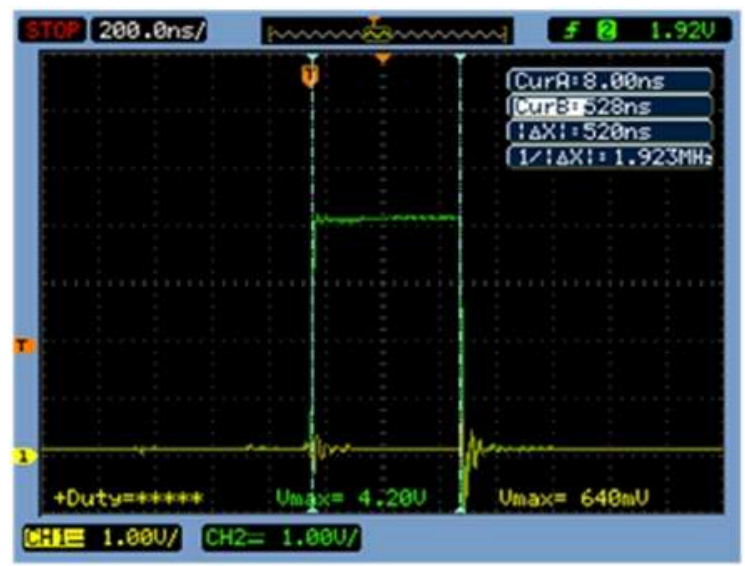

Figure 21 Experimental results when $Z 2$ is activated from the decision block for a non-fault condition

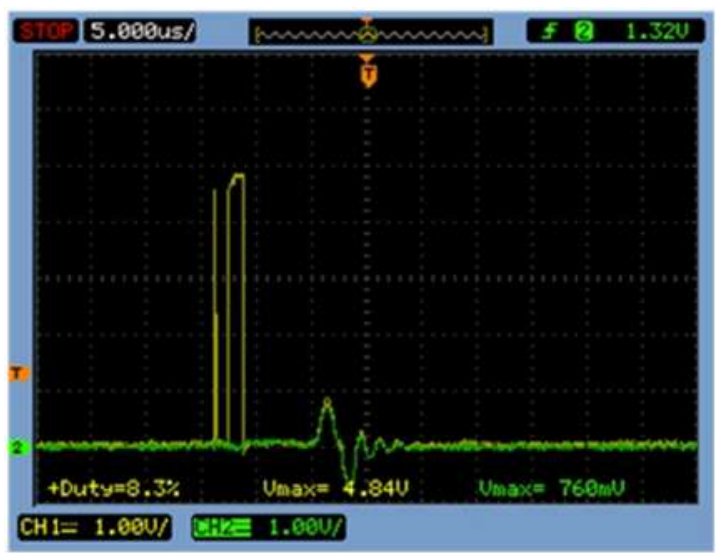

Figure 22 Experimental results when $Z 3$ and $Z 2$ are activated from the decision block for an open-circuit fault condition

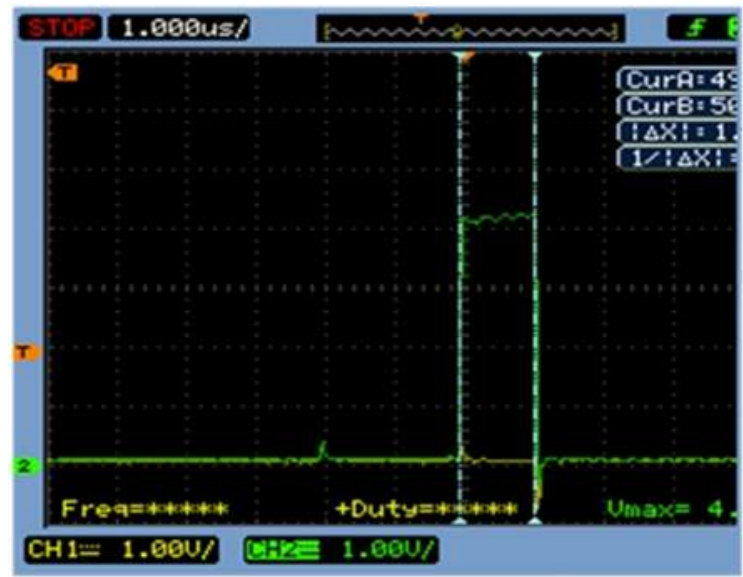

Figure 23 Experimental results when $Z 1$ and $Z 2$ are activated from the decision block for a short-circuit fault condition

\section{Conclusions}

In this paper has been presented simulation and experimental results for an early fault detection system applied for a SiC-Mosfet. The objective was to obtain early fault detection for a high dynamic system like the SiC-Mosfet on a switching power supply. In order to validate the system, the gate signal was analyzed for different fault conditions (non-fault, short-circuit fault and open circuit fault). According with the results the fault was mitigated making use of a replacement component to avoid the propagation of the fault. Future work includes the incorporation of the thresholds making use of an adaptive algorithm to improve the robustness of the proposed system.

\section{References}

[1] R. Singh, "Reliability and performance limitations in sic power devices," Microelectronics Reliability, vol. 46, no. 5-6, pp. 713-730, May 2006

[2] A. A. et. al., "Progress in silicon carbide power devices," in 64th IEEE Devices Research Conference, Pennsylvania, USA, 2006, pp. 155-158.

[3] J. C. Zolper, “Emerging silicon carbide power electronics components," in 20th Annu. IEEE Appl. Power Electron. Conf., Austin, TX, USA, 2005, pp. 11-17.

[4] M. Holz, G. Hultsch, T. Scherg, and R. Rupp, "Reliability considerations for recent infineon sic diode releases," Microelectronics Reliability, vol. 47, no. 9-11, pp. 1741-1745, Sep 2007.

[5] R. S. Chokhawala and S. Sobhani, "Switching voltage transient protection schemes for high-current igbt modules," IEEE Trans. Ind. Appl., vol. 33, no. 6, pp. 1601-1610, Nov 1997.

[6] R. S. Chokhawala, J. Catt, and L. Kiraly, "A discussion on igbt shortcircuit behavior and fault protection schemes," IEEE Trans. Ind. Appl., vol. 31, no. 2, pp. 256-263, Mar 1995.

[7] R. Pagano, K. S. Y. Chen, S. Musumeci, and A. Raciti, “Short circuit analysis and protection of power module igbts," in 20th Annu. IEEE Appl. Power Electron. Conf., Austin, TX, USA, 2005, pp. 777-783.

[8] F. Huang and F. Flett, “Igbt fault protection based on di/dt feedback control," in IEEE Power Electronics Specialists, Orlando, Florida, USA, 2007, pp. 1913-1917.

[9] B. G. Park, J. B. Lee, and D. S. Hyun, “A novel short-circuit detecting scheme using turn-on switching characteristic of igbt," in IEEE Industry Applications Society Annual Meeting, Edmonton, Canada, 2008, pp. 1-5.

[10] T. J. Klim, W. C. Lee, and D. S. Hyun, “Detection method for open-circuit fault in neutral-point-clamped inverter systems," IEEE Trans. Ind. Electron., vol. 56, no. 7, pp. 2754-2763, Mar 2009.

[11] W. Sleszynski, J. Nieznanski, and A. Cichowski, “Open-transistor fault diagnostics in voltage-source inverters by analyzing the load currents," IEEE Trans. Ind. Electron., vol. 56, no. 11, pp. 4681-4688, Jun 2009.

[12] K. Rothenhagen and F. W. Fuchs, "Performance of diagnosis methods for igbt open circuit faults in three phase voltage source inverters for ac variable speed drives," in Proc. Eur. Conf. Power Electron. Appl., Dresden, Germany, 2005, pp. 1-10.

[13] Y. X. et al., "Prognostic and warning system for power-electronic modules in electric, hybrid electric, and fuel-cell vehicles," IEEE Trans. Ind. Electron., vol. 55, no. 6, pp. 2268-2276, May 2008.

[14] J. Klima, "Analytical investigation of an induction motor drive under inverter fault mode operations," IEEE Proc. Elect. Power Appl., vol. 150, no. 3, pp. 255-262, May 2003.

[15] M. A. R. et al., "A failure detection strategy for igbt based on gate 
voltage behavior applied to a motor drive system," IEEE Trans. Ind. Electron., vol. 58, no. 5, pp. 1625-1633, May 2011.

[16] M. R. et al., "Aspectos críticos en el diseño de un circuito de detección de fallas en el igbt basado en la medición de la señal de compuerta," in Congreso Internacional sobre Innovación y Desarrollo Tecnológico, Cuernavaca Morelos, México, 2010, pp. 1-5.

[17] M. A. R. et al., "Study of a novel electronics circuit for detecting faults in the igbt," IEEE Latin America Transactions, vol. 12, no. 3, pp. 402-409, May 2014.
[18] Cree Company. (2016) C2m0040120d silicon carbide power mosfet. Accessed December, 2016. [Online]. Available: https: //www.wolfspeed.com/power/products/sic-mosfets/table

[19] B. Baliga, Fundamentals of Power Semiconductor Devices, 1st ed. USA: Springer, 2018.

[20] N. Mohan, T. M. Undeland, and W. P. Robbins, Power Electronics Converter Applications and Design, 2nd ed. New York USA: John Wiley \& Sons INC, 1995. 